\title{
PENGARUH PERUBAHAN BIAYA TRANSAKSI KARTU ATM (ANJUNGAN TUNAI MANDIRI) PADA TABUNGAN FAEDAH TERHADAP MINAT BERTRANSAKSI NASABAH DI BRISYARIAH KC SEMARANG
}

\author{
Imam Yahya dan Retnandi Meita Putri ${ }^{1}$
}

\begin{abstract}
The more advanced information technology, the more frequently for banking institutions including BRI Syariah to follow and to use it as a part of service system, that is called as electronic banking. The growth of technology will change banking transaction system radically that eventually will change banking culture. The transaction through electronic banking will ease the customers in doing transaction therefore they are able to opt various services related to their need.

Tabungan Faedah BRISyariah delivers affordable and easy service by using electronic banking in which all the transactions are free of charge. It starts from cash withdrawal, money transfer to BRISyariah ATM network, BRI Bank, Prima and Bersama. However, since May 6 2015, there was a transaction charge change especially for transaction in Issuer ATM that is BRI ATM, Prima and Bersama. Since the regulation was applied, the number of transactions also changed. According to the data of BRISyariah Issuer ATM transaction from January to December 2015, the total transaction declined. This research is aimed to discover the influence of transaction charge change of ATM card in faedab banking account to the costumers' proclivity in BRISyariah KC Semarang.
\end{abstract}

The transaction charge change of ATM card having positive influence and significance towards the costumer's proclivity. The transaction charge such as cash withdrawal, money transfer, and balance check which is very expensive makes the customer's proclivity declined. It is proved by the value of t-count is $2.878>t$-table which is 2.024 by the degree od significance is 0.000 below 0.05 .

Keywords: Transaction Charge Change in Faedab banking account's ATM card, proclivity of having transaction.

\footnotetext{
${ }^{1}$ Fakultas Ekonomi dan Bisnis Islam, UIN Walisongo Semarang
}

Volume VII/Edisi 1/Mei 2016 
Pengaruh Perubahan Biaya Transaksi...

\section{Pendahuluan}

Dunia bisnis perbankan syariah saat ini mengalami kemajuan dan perkembangan yang pesat. Maraknya perkembangan perbankan syariah di Indonesia yang tidak berbasis bunga, melahirkan begitu banyak para investor dan nasabah dengan berbagai penghimpunan dana. ${ }^{2}$ Tingginya keinginan masyarakat terhadap bank syariah dalam menabung serta pembiayaan membuat bisnis jasa dalam perbankan syariah semakin prospektif. Bank syariah menjadi tempat untuk menghimpun dan menyalurkan dana bagi masyarakat yang mempunyai misi berlandaskan keadilan, kejujuran, kemanfaatan, kebersamaan yang sesuai dengan syariah. ${ }^{3}$ Selama penghimpunan dan penyaluran dana masih berlangsung, maka bisnis jasa bank syariah tidak akan berhenti. Kondisi ini menunjukkan bahwa masyarakat masih membutuhkannya. Situasi ini memberikan peluang bagi pengelola bank syariah untuk menekuni usaha tersebut.

Perkembangan bisnis jasa perbankan syariah yang semakin berkembang, membuat persaingan dalam perbankan syariah semakin ketat terutama bagi usaha yang sasaran segmen pasarnya serupa. Hal ini dibuktikan dengan banyaknya bank syariah yang berdiri di Indonesia. Timbulnya tingkat persaingan dalam perbankan syariah ditandai dengan maraknya produk dan jasa yang ditawarkan dalam bank syariah. ${ }^{4}$ Sehingga para pelaku bisnis dituntut untuk menciptakan suatu keunggulan dibanding dengan para pesaing. Salah satu bank yang ada di Indonesia adalah BRISyariah.

Berawal dari akuisisi PT Bank Rakyat Indonesia (Persero), Tbk., terhadap Bank Jasa Arta pada tanggal 19 Desember 2007 dan setelah mendapat izin dari Bank Indonesia pada 16 Oktober 2008 melalui suratnya o.10/67/KEP.GBI/DpG/2008, maka pada tanggal 17 November 2008 PT. Bank BRISyariah secara resmi beroperasi. Kemudian PT. Bank BRISyariah merubah kegiatan usaha yang semula beroperasional secara konvensional, kemudian diubah menjadi kegiatan perbankan berdasarkan prinsip syariah Islam. Aktivitas PT. Bank BRISyariah semakin kokoh setelah pada 19 Desember 2008 ditandatangani akta pemisahan Unit Usaha Syariah PT Bank

\footnotetext{
2 Mansur, Ekonomi Islam, Salatiga: STAIN Salatiga Press, 2009, hlm. 66.

3 Andri Soemitra, Bank \& Lembaga Kenangan Syariah, Jakarta: Kencana, 2009, hlm. 25.

${ }^{4}$ Kasmir, Bank dan Lembaga Keuangan Lainnya, Jakarta: PT Raja Grafindo Persada, 2003, hlm. 292.
} 
Rakyat Indonesia (Persero), Tbk., untuk melebur ke dalam PT. Bank BRISyariah (proses spin off) yang berlaku efektif pada tanggal 1 Januari 2009. Saat ini PT. Bank BRISyariah menjadi bank syariah ketiga terbesar berdasarkan aset. PT. Bank BRISyariah tumbuh dengan pesat baik dari sisi aset, jumlah pembiayaan, dan perolehan dana pihak ketiga. Dengan berfokus pada segmen menengah ke bawah, PT. Bank BRISyariah menargetkan menjadi bank ritel modern terkemuka dengan berbagai ragam produk dan layanan perbankan.

Sebagai bank yang berkonsentrasi pada segmen ritel menengah bawah dalam memberikan servis keuangan dan layanan perbankan, PT. Bank BRISyariah mengandalkan Tabungan BRISyariah iB dalam penggalangan Dana Pihak Ketiganya. PT. Bank BRISyariah memberikan fasilitas yang serba mudah dan murah melalui tabungannya. Produk tabungan BRISyariah yang mudah dan murah itu bernama Tabungan Faedah BRISyariah iB. Faedah bermakna fasilitas serba mudah. ${ }^{5}$ Tabungan ini sesuai dengan namanya yang memiliki banyak faedah. Namun hal yang terpenting adalah memberi ketenangan serta kenyamanan yang penuh nilai kebaikan serta lebih berkah karena pengelolaan dana sesuai syariah.

Dengan semakin majunya teknologi informasi, lembaga perbankan termasuk BRISyariah yang sarat dengan teknologi harus mengikuti dan menggunakan teknologi ini sebagai bagian dari sistem pelayanannya, yang dikenal dengan electronic banking. Perkembangan teknologi akan mengubah radikal sistem transaksi perbankan, yang akhirnya mengubah budaya perbankan. ${ }^{6}$ Transaksi melalui sistem electronic banking ini akan mempermudah nasabah dalam melakukan transaksinya sehingga nasabah dapat memilih berbagai layanan sesuai kebutuhannya. Secara umum, sistem layanan perbankan yang menggunakan electronic banking yaitu ATM Banking, Kartu Debit, Kartu Kredit, Internet Banking, SMS Banking, Call Banking, Phone Banking, IP Phone Banking, dan kartu penarikan fasilitas lain, termasuk sarana bayar lainnya. ${ }^{7}$

\footnotetext{
${ }^{5}$ www.brisyariah.co.id, diakses 1 Maret 2016.

6 Try Widiyono, Aspek Hukum Operasional Transaksi Produk Perbankan di Indonesia, Bogor: Ghalia Indonesia, 2006, hlm. 197.

${ }^{7}$ Ibid, hlm. 195.
} 
Pengarub Perubahan Biaya Transaksi...

Dalam Tabungan Faedah, BRISyariah memberikan pelayanan yang murah dan mudah dengan sistem electronic banking yaitu dengan cara menggratiskan segala macam transaksi, mulai dari tarik tunai, transfer hingga pembayaran pajak dan zakat di jaringan ATM BRISyariah, ATM Bank BRI, ATM Prima dan ATM Bersama. Selain itu BRISyariah juga membebaskan biaya administrasi, setoran awal yang rendah, saldo minimal sangat kecil. ${ }^{8}$ Namun semenjak tanggal 6 Mei 2015, terjadi perubahan biaya transaksi pada Tabungan Faedah BRISyariah iB, terutama untuk transaksi di mesin ATM Issuer yaitu ATM BRI, Prima dan Bersama. Berikut perubahannya:

Tabel 1 Perubahan Biaya Transaksi kartu ATM di ATM Issuer

\begin{tabular}{|c|c|c|c|c|c|}
\hline \multirow[b]{3}{*}{ No } & \multirow[b]{3}{*}{ Jenis Transaksi } & \multicolumn{4}{|c|}{ Biaya Transaksi } \\
\hline & & \multicolumn{2}{|c|}{ Tahun 2014} & \multicolumn{2}{|c|}{ Tahun 2015} \\
\hline & & $\begin{array}{l}\text { Saldo Sebelum } \\
\text { Transaksi } \\
\text { Kurang dari } \\
\text { Rp.500.000 }\end{array}$ & $\begin{array}{c}\text { Saldo } \\
\text { Sebelum } \\
\text { Transaksi } \\
\text { Sama } \\
\text { Dengan atau } \\
\text { Lebih dari } \\
\text { Rp. } 500.000\end{array}$ & $\begin{array}{c}\text { Saldo } \\
\text { Sebelum } \\
\text { Transaksi } \\
\text { Kurang dari } \\
\text { Rp.500.000 }\end{array}$ & $\begin{array}{c}\text { Saldo } \\
\text { Sebelum } \\
\text { Transaksi } \\
\text { Sama } \\
\text { Dengan atau } \\
\text { Lebih dari } \\
\text { Rp.500.000 }\end{array}$ \\
\hline 1 & $\begin{array}{l}\text { Jaringan ATM BRI } \\
\text { - Tarik tunai } \\
\text { - Cek Saldo } \\
\text { - Transfer } \\
\text { - Ke BRISyariah } \\
\text { - Ke Bank BRI } \\
\text { - Ke Jar. Bersama } \\
\text { - Ke Jar. Prima }\end{array}$ & $\begin{array}{l}\text { Gratis } \\
\text { Gratis } \\
\text { Gratis } \\
\text { Gratis } \\
\text { Gratis } \\
\text { Gratis }\end{array}$ & $\begin{array}{l}\text { Gratis } \\
\text { Gratis } \\
\text { Gratis } \\
\text { Gratis } \\
\text { Gratis } \\
\text { Gratis }\end{array}$ & $\begin{array}{l}3.500 \\
2.500 \\
2.000 \\
5.000 \\
6.500 \\
6.500\end{array}$ & $\begin{array}{l}1.750 \\
1.250 \\
1.000 \\
2.500 \\
3.250 \\
3.250\end{array}$ \\
\hline 2 & $\begin{array}{l}\text { Jaringan ATM } \\
\text { Bersama } \\
\text { - Tarik tunai } \\
\text { - Transfer } \\
\text { - Cek Saldo }\end{array}$ & $\begin{array}{l}7.500 \\
6.500 \\
4.000\end{array}$ & $\begin{array}{l}\text { Gratis } \\
\text { Gratis } \\
\text { Gratis }\end{array}$ & $\begin{array}{l}7.500 \\
6.500 \\
4.000\end{array}$ & $\begin{array}{l}3.750 \\
3.250 \\
2.000\end{array}$ \\
\hline 3 & $\begin{array}{l}\text { Jaringan ATM Prima } \\
\text { - Tarik tunai } \\
\text { - Transfer } \\
\text { - Cek Saldo }\end{array}$ & $\begin{array}{l}7.500 \\
6.500 \\
4.000\end{array}$ & $\begin{array}{l}\text { Gratis } \\
\text { Gratis } \\
\text { Gratis }\end{array}$ & $\begin{array}{l}7.500 \\
6.500 \\
4.000\end{array}$ & $\begin{array}{l}3.750 \\
3.250 \\
2.000\end{array}$ \\
\hline
\end{tabular}

Sumber: New Faedah BRISyariah yang diolah, 2016

Sejak terjadi perubahan biaya transaksi pada tabungan Faedah BRISyariah, maka jumlah transaksi di ATM (Anjungan Tunai Mandiri) Issuer

${ }^{8}$ www.brisyariah.co.id, diakses 1 Maret 2016. 
juga mengalami perubahan. ATM merupakan sebuah perangkat komputerisasi yang digunakan oleh suatu lembaga keuangan (bank) dalam upaya menyediakan layanan transaksi keuangan. Sebagaimana tabel data di bawah ini:

Tabel 2 Transaksi ATM Issuer BRISyariah

TRANSAKSI ATM ISSUER BRISYARIAH

JANUARI - DESEMBER 2015

\begin{tabular}{|l|c|c|c|c|c|c|}
\hline \multirow{2}{*}{ ISSUER } & \multicolumn{5}{c|}{ FREKUENSI TRANSAKSI PER TANGGAL } \\
\cline { 2 - 7 } & JAN & FEB & MAR & APR & MEI & JUN \\
\hline INQUIRY & & & & & & \\
\hline $\begin{array}{l}\text { ATM } \\
\text { BERSAMA }\end{array}$ & 202440 & 166184 & 187561 & 162941 & 164073 & 135435 \\
\hline ATM PRIMA & 58059 & 46893 & 59740 & 63021 & 42706 & 32399 \\
\hline $\begin{array}{l}\text { WITHDRAWAL } \\
\text { ATM }\end{array}$ & & & & & & \\
\hline BERSAMA & 364876 & 314139 & 364000 & 331804 & 349354 & 280320 \\
\hline ATM PRIMA & 92394 & 77313 & 92202 & 84084 & 81162 & 67511 \\
\hline $\begin{array}{l}\text { RATA-RATA } \\
\text { FREKUENSI } \\
\text { PERBULAN }\end{array}$ & 179442 & 151132 & 175875.8 & 160463 & 159324 & 128916 \\
\hline
\end{tabular}

\begin{tabular}{|c|c|c|c|c|c|c|}
\hline \multirow{2}{*}{ ISSUER } & \multicolumn{6}{|c|}{ FREKUENSI TRANSAKSI PER TANGGAL } \\
\hline & JUL & AGT & SEP & OKT & NOV & DES \\
\hline \multicolumn{7}{|l|}{ INQUIRY } \\
\hline $\begin{array}{l}\text { ATM } \\
\text { BERSAMA }\end{array}$ & 138229 & 126063 & 99147 & 100245 & 101596 & 105595 \\
\hline ATM PRIMA & 29548 & 26453 & 24654 & 27633 & 26462 & 26916 \\
\hline \multicolumn{7}{|c|}{ WITHDRAWAL } \\
\hline $\begin{array}{l}\text { ATM } \\
\text { BERSAMA }\end{array}$ & 275481 & 257488 & 228147 & 221402 & 212861 & 220067 \\
\hline ATM PRIMA & 63933 & 59553 & 54567 & 52295 & 51058 & 52207 \\
\hline $\begin{array}{l}\text { RATA-RATA } \\
\text { FREKUENSI } \\
\text { PERBULAN }\end{array}$ & 126798 & 117389 & 101629 & 100394 & 97994 & 101196 \\
\hline
\end{tabular}

Sumber: Transaksi ATM Issuer BRISyariah Januari-Desember 2015 yang diolah, 2016

Data di atas merupakan jumlah transaksi di ATM Issuer yaitu di mesin ATM Bersama maupun Prima untuk transaksi inquiry (permintaan baik cek saldo, transfer) dan withdrawal (penarikan). Perubahan jumlah transaksi akan lebih terlihat jelas melalui diagram garis di bawah ini. 
Pengaruh Perubahan Biaya Transaksi...

Gambar 1 Rata-Rata Frekuensi Perbulan Transaksi ATM Issuer BRISyariah

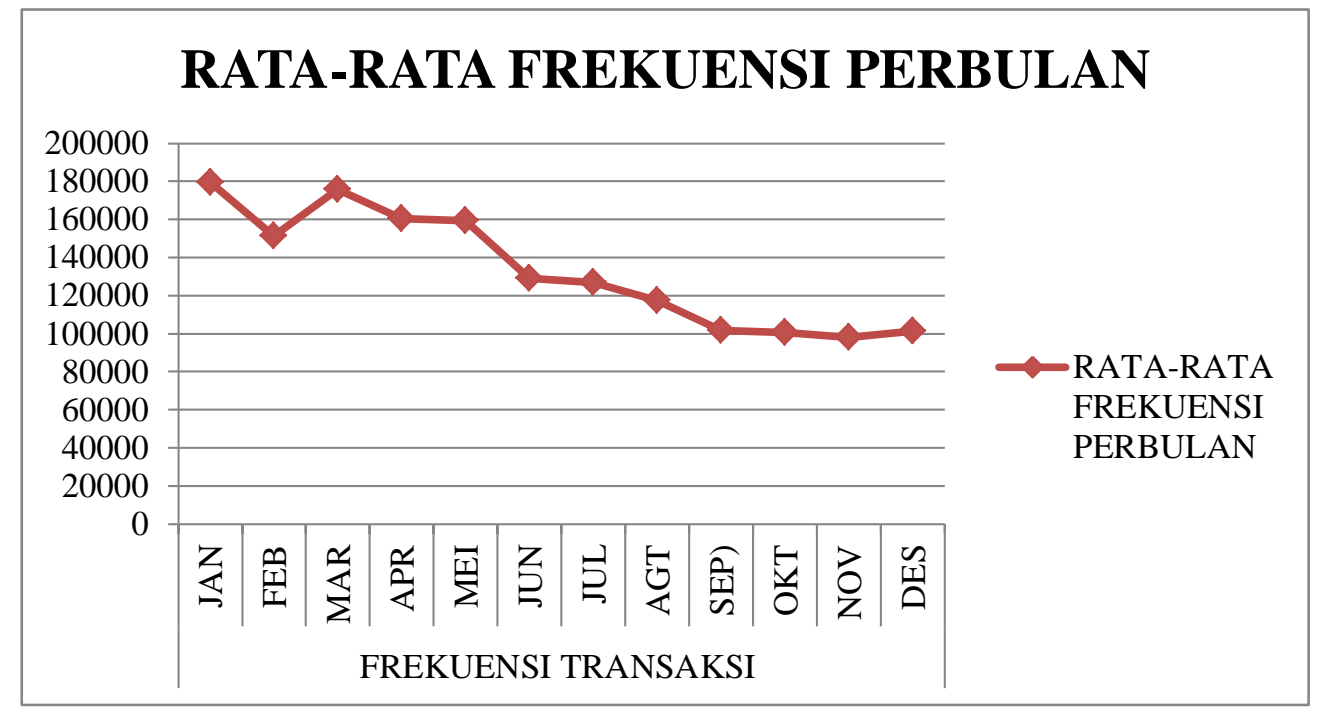

Sumber: Transaksi ATM Issuer BRISyariah Januari-Desember 2015 yang diolah, 2016

Sebelum terjadi perubahan biaya transaksi pada ATM, jumlah transaksi pada bulan Januari sampai April dalam keadaan yang fluktuatif namun masih dalam jumlah yang tinggi. Sedangkan pada saat terjadi perubahan biaya pada bulan Mei, jumlah transaksi yang terjadi sampai bulan Desember mengalami penurunan.

Berdasarkan data di atas, maka perubahan biaya transaksi pada Tabungan Faedah BRISyariah khususnya biaya transaksi pada kartu ATM tersebut menjadi perhatian utama bagi nasabah. Sebagaimana penelitian yang dilakukan oleh Ali Hasan dalam bukunya Manajemen Pemasaran Bank Syariah yang menunjukkan bahwa 40\% dari 897 nasabah menggunakan produk bank berdasarkan tingkat price (jasa, provisi, biaya transfer, hadiah dan lainnya) yang menguntungkan nasabah. ${ }^{9}$ Hasil tersebut merupakan hasil terbesar dibandingkan dengan kepedulian manajemen, kualitas produk, kemudahan transaksi, dan kualitas layanan. Hal ini dikarenakan nasabah menggunakan produk perbankan bukan hanya untuk menabung atau melakukan pembiayaan, melainkan juga untuk melakukan transaksi pembelian, pembayaran barang dan

${ }^{9}$ Ali Hasan, Marketing Bank Syariah, Bogor: Penerbit Ghalia Indonesia, 2010, hlm. 81. 
jasa serta kegiatan transaksi lainnya untuk memenuhi kebutuhan yang cepat, mudah, dan murah. Apalagi kegiatan transaksi nasabah sering dilakukan untuk memenuhi kebutuhannya. Oleh karena itu, penelitian ini bertujuan untuk mengetahui apakah dengan terjadinya perubahan biaya transaksi kartu ATM pada Tabungan Faedah berpengaruh terhadap minat bertransaksi nasabah di BRISyariah KC Semarang.

\section{Telaah Teoritis}

1. Perubahan Biaya Transaksi

Perubahan adalah suatu peralihan dari suatu hal menjadi hal lain. Biaya adalah nilai tukar, pengeluaran, pengorbanan untuk memperoleh manfaat. ${ }^{10}$ Sedangkan transaksi adalah persetujuan jual beli (dalam perdagangan) antara dua pihak atau pelunasan dan pembayaran. Sedangkan biaya transaksi adalah biaya selain harga barang atau asa yang dikeluarkan dalam perdagangan barang atau jasa.

Perubahan biaya transaksi adalah besar pengeluaran atau pengorbanan yang mengalami perubahan untuk memperoleh manfaat yaitu untuk melakukan pembayaran atau pelunasan (kegiatan perdagangan) untuk memenuhi kebutuhan.

2. Kartu ATM

ATM adalah sebuah perangkat komputerisasi yang digunakan oleh suatu lembaga keuangan (bank) dalam upaya menyediakan layanan transaksi keuangan. ${ }^{11}$ ATM merupakan mesin yang dapat melayani kebutuhan nasabah secara otomatis setiap saat $(24$ jam) dan 7 hari dalam seminggu termasuk hari libur. Lokasi ATM tersebar di tempat-tempat strategis. Pengertian ATM dewasa ini sudah diterjemahkan ke dalam bahasa Indonesia yang artinya Anjungan Tunai Mandiri. ${ }^{12}$ Dengan kata lain, kartu ATM merupakan sistem modern dalam transaksi yang diinginkan oleh pemegang kartu ATM melalui suatu jaringan sistem elektronik yang canggih.

${ }^{10}$ Ony Widilestariningtyas, et al., Akuntansi Biaya, Yogyakarta: Graha Ilmu, 2008, hlm. 2.

11 Muchammad Fauzi, "Pengaruh Kinerja Anjungan Tunai Mandiri (ATM) terhadap Kepercayaan Partisipasi Relationship dan Loyalitas Nasabah Bank Syariah di Jawa Tengah", Jurnal Pemikiran dan Penelitian Ekonomi Islam, Volume II, Edisi 1, Mei 2011, hlm. 66

12 Kasmir, Dasar-Dasar Perbankan, Jakarta: PT RajaGrafindo Persada, 2002, hlm. 182. 
Pengarub Perubahan Biaya Transaksi...

Fasilitas layanan ini dibuat antara lain untuk menarik dana nasabah melalui cross selling dan untuk meningkatkan fee based income. ${ }^{13}$ Oleh karena itu, layanan ATM merupakan bagian dan berinduk kepada rekening tabungan dan atau giro. Konsekuensi dari sistem demikian, ketentuanketentuan dalam produk tabungan atau giro berlaku pada produk layanan kartu ATM, kecuali secara tegas ketentuan tersebut diatur dalam formulir syarat dan ketentuan dalam layanan kartu ATM. Azaz ini berlaku umum dikesampingkan oleh ketentuan yang khusus.

ATM biasanya dapat digunakan dalam transaksi menggunakan ATM bank yang bersangkutan dan atau lembaga keuangan lainnya (lintas network), yaitu mesin ATM milik peserta dari jaringan berdasarkan perjanjian bersama dan atau pada mesim-mesin ATM yang berlogo tertentu (biasanya logonya terdapat pada kartu ATM). Apabila nasabah menggunakan fasilitas mesin ATM di luar mesin ATM milik bank lain, maka akan dikenakan charge yang besarnya ditentukan oleh kesepakatan bersama antara para pemilik jaringan ATM bersama tersebut. ${ }^{14}$ Oleh karena itu, nasabah harus mengetahui berapa biaya yang dikenakan jika nasabah menggunakan kartu ATM pada mesin ATM bank lain. Hal ini berkaitan dengan adanya acquiring fee, yaitu fee yang diperoleh atas transaksi ATM di bank lain.

Hal ini yang terpenting dari kartu ATM adalah fungsi yang diberikan oleh kartu tersebut karena masing-masing kartu mempunyai fungsi yang berbeda-beda, sesuai dengan kecanggihan jaringan teknologi yang dimiliki oleh bank yang bersangkutan. Oleh karena itu, pemegang kartu ATM wajib mengetahui fungsi kartu yang dimiliki. Beberapa diantaranya adalah sebagai berikut: 15

1) Sebagai sarana untuk membuka rekening lain yang ditawarkan oleh bank bank yang bersangkutan, misalnya internet banking dan atau call banking.

\footnotetext{
${ }^{13}$ Widiyono, Aspek..., hlm. 199.

${ }^{14}$ Ibid

${ }^{15} \mathrm{Ibid}, \mathrm{hlm} .200$.
} 
2) Sebagai sarana untuk melakukan transaksi lain, misalnya perintah permindah bukuan atau transfer pada rekening yang ada pada bank yang sama. Closed transfer, yaitu pemindah bukuan antar rekening nasabah yang terdapat pada satu nomor kartu pada cabang yang sama, permintaan rekening koran, permintaan kartu cek dan atau bilyet giro (rekening koran, cek bilyet giro ini, biasanya tetap diambil di cabang dan tidak keluar dari mesin ATM).

3) Sebagai sarana pembayaran pada merchant-merchant tertentu (toko, hotel, biro perjalanan, kafe, dan lain sebagainya)

4) Sebagai sarana penarikan kredit (kartu kredit)

5) Sarana-sarana lain yang sesuai dengan fitur yang ditawarkan kepada nasabah.

6) Sarana perintah untuk dapat melihat atau mengecek saldo rekening nasabah

7) Sarana perintah untuk dapat melakukan penarikan uang tunai.

3. Minat Bertransaksi

Minat adalah kesukaan (kecenderungan hati) kepada sesuatu, perhatian, dan keinginan. ${ }^{16}$ Minat merupakan suatu kecenderungan untuk memberikan perhatian dan bertindak terhadap orang, aktivitas, atau situasi yang menjadi obyek dari minat tersebut disertai perasaan senang. Minat adalah suatu keadaan di mana seseorang mempunyai perhatian terhadap suatu objek dan disertai dengan keinginan untuk mengetahui, mempelajari, dan untuk membuktikannya lebih lanjut tentang objek tertentu dengan perngertian aktif terhadap objek tersebut.

Berdasarkan definisi di atas bahwa minat itu merupakan motivasi yang mendorong orang untuk melakukan apa yang mereka inginkan bila mereka bebas memilih, bila mereka melihat bahwa sesuatu akan menguntungkan, mereka merasa berminat.

${ }^{16}$ Wjs. Poerwadarmata, Kamus Umum Bahasa Indonesia, Jakarta: Balai Pustaka, 2006, hlm. 1181. 
Pengarub Perubahan Biaya Transaksi...

Minat bertransaksi adalah kecenderungan untuk memberikan perhatian dan bertindak pada orang atau sesuatu yang berhubungan dengan sikap untuk memutuskan menggunakan produk dan atau jasa atau tidak.

Karena minat dalam hal ini berhubungan dengan transaksi nasabah di bank, maka hal ini berhubungan pula dengan perilaku nasabah. Perilaku nasabah atau consumer behavior menurut Bagozzi dan Zaltman adalah tindakan-tindakan, proses, dan hubungan sosial yang ditampilkan oleh individu, kelompok, dan organisasi dalam mendapatkan atau menggunakan suatu produk atau lainnya sebagai suatu akibat dari pengalamannya dengan produk, pelayanan, dan dengan sumber-sumber lainnya. Sedangkan consumer behavior menurut John Mowen adalah studi tentang unit pembelian (buying units) dan proses-proses pertukaran yang dilibatkan dalam mendapatkan, mengonsumsi, dan mengelola barang, jasa, pengalaman, dan ide. ${ }^{17}$ Sehingga perilaku nasabah atau consumer behavior adalah respon psikologis yang kompleks yang muncul dalam bentuk perilaku atau tindakan yang khas secara perseorangan yang langsung terlibat dalam usaha memperoleh, menggunakan produk, dan menentukan proses pengambilan keputusan dalam melakukan pembelian produk, termasuk dalam pembelian ulang.

4. Faktor-Faktor yang Mempengaruhi Perilaku Nasabah dalam Membeli (Bertransaksi)

Faktor-faktor yang mempengaruhi perilaku nasabah dalam membeli, yaitu: ${ }^{18}$

1) Faktor lingkungan

Seperti tingkat permintaan dari nasabah, keadaan ekonomi, biaya, tingkat perubahan teknologi, perkembangan teknologi, politik, dan undang-undang.

2) Faktor organisasi

Seperti tujuan organisasi, kebijakan, prosedur, struktur organisasi, dan sistem.

3) Faktor antarindividu

${ }^{17}$ Herry Sutanto dan Khaerul Umam, Manajemen Pemasaran Bank Syariah, Bandung: Pustaka Setia, 2013, hlm. 306-307.

${ }^{18}$ Ibid, hlm. 311-312. 
Seperti wewenang, status, empati, persuasi. Buying center (pusat pembelian) sebuah organisasi biasanya melibatkan beberapa orang yang memiliki kepentingan, wewenang dan kepandaian membujuk yang berbeda.

4) Faktor individu

Seperti umur, gaji, pendidikan, jabatan, kepribadian, resiko.

5. Proses Pembelian Konsumen

Proses pembelian konsumen, yaitu: ${ }^{19}$

1) Pengenalan masalah

Proses pembelian dimulai ketika pembeli mengenali masalah atau kebutuhan. Dalam hal ini mengenai kebutuhan nasabah akan produk dan jasa perbankan syariah

2) Pencairan informasi

Hal ini dilakukan dengan mengumpulkan data untuk memenuhi kebutuhan nasabah. Pencairan informasi ini bisa didapatkan dari teman, keluarga, tetangga, iklan, brosur, lembaga, dan lain sebagainya.

3) Evaluasi alternatif

Hal ini berhubungan dengan kriteria seleksi, yaitu tangibility, accesability, reliability, responsibility, emphaty, dan jaminan kualitas produk. Misalnya dalam hal seleksi ini dikarenakan harga yang ditawarkan murah.

4) Keputusan pembelian

Setelah evaluasi alternatif, maka proses selanjutnya yaitu keputusan membeli atau tidak.

5) Perilaku pascapembelian

Hal ini berhubungan dengan tingkat kepuasan. Dan mempengaruhi untuk keputusan selanjutnya apakah akan menggunakan produk tersebut lagi atau tidak.

${ }^{19}$ Philip Kotler, Manajemen Pemasaran Jilid 1, Jakarta: Indeks, 2005, hlm. 224-228. 
Pengaruh Perubahan Biaya Transaksi...

\section{Metodologi}

Populasi dalam penelitian ini adalah semua nasabah yang memiliki rekening Tabungan Faedah dengan fasilitas ATM sebesar 22.845 nasabah. ${ }^{20}$ Data jumlah nasabah ini merupakan jumlah nasabah pengguna rekening tabungan Faedah pada bulan Maret 2016.

Sampel yaitu sebagian dari jumlah dan karakteristik yang dimiliki oleh populasi tersebut. ${ }^{21}$ Dapat juga diartikan bagian kecil dari suatu populasi yang karakteristiknya hendak diselidiki dan dianggap dapat mewakili dari keseluruhan populasi atau wakil populasi yang diteliti. Banyaknya nasabah di BRISyariah menjadikan jumlah populasi terlalu banyak dan peneliti tidak mungkin mempelajari semua yang ada pada populasi karena adanya keterbatasan dana, waktu, dan tenaga. Menurut Roscoe dalam buku Sugiyono, "Ukuran sampel yang layak dalam peneitian adalah antara 30 sampai 500."22 Maka peneliti menggunakan sampel 40 nasabah.

Teknik yang digunakan dalam pengambilan sampel dalam penelitian ini adalah purposive sampling, yaitu responden yang terpilih menjadi anggota sampel atas dasar pertimbangan tertentu. ${ }^{23}$ Pertimbangan tersebut, yaitu:

1. Nasabah memiliki tabungan Faedah dengan fasilitas ATM dengan jangka waktu miminal 3 tahun.

2. Melakukan transaksi di mesin ATM minimal sebanyak 4 kali dalam sebulan.

Variabel Penelitian dan Pengukuran

\begin{tabular}{|l|l|l|l|}
\hline $\begin{array}{c}\text { Variabel } \\
\text { Penelitian }\end{array}$ & \multicolumn{1}{|c|}{ Definisi } & \multicolumn{1}{c|}{ Indikator } & \multicolumn{1}{c|}{$\begin{array}{c}\text { Skala } \\
\text { Pengukuran }\end{array}$} \\
\hline Perubahan & Perubahan biaya pada & a. Biaya Transfer & Diukur melalui \\
Biaya & suatu sistem modern & b. Biaya Tarik & angket dengan \\
Transaksi & dalam transaksi yang & \multicolumn{1}{|c|}{ Tunai } & $\begin{array}{l}\text { menggunakan } \\
\text { skala likert. }\end{array}$ \\
pada kartu & diinginkan oleh & c. Biaya Cek Saldo & \\
pemegang kartu ATM & & \\
\hline
\end{tabular}

${ }^{20}$ Wawancara dengan Manajer Operasional BRISyariah KC Semarang pada tanggal 15 April 2016.

${ }^{21}$ Sugiyono, Statistik Untuk Penelitian, Bandung: Alfabeta, 2005, hlm. 56

${ }^{22}$ Sugiyono, Metode Penelitian Kombinasi (Mixed Methods), Bandung: Alfabeta, 2011, hlm. 133.

23 Sugiyono, Statistik..., hlm. 68. 
Imam Yabya \& Retnandi

\begin{tabular}{|c|c|c|c|}
\hline & $\begin{array}{l}\text { sistem elektronik yang } \\
\text { canggih. }\end{array}$ & & \\
\hline $\begin{array}{l}\text { Minat } \\
\text { Bertransak } \\
\text { si Nasabah } \\
\text { (Y) }\end{array}$ & $\begin{array}{l}\text { Kecenderungan untuk } \\
\text { memberikan perhatian } \\
\text { dan bertindak pada } \\
\text { orang atau sesuatu } \\
\text { yang berhubungan } \\
\text { dengan sikap untuk } \\
\text { memutuskan } \\
\text { menggunakan produk } \\
\text { dan atau jasa atau tidak. }\end{array}$ & $\begin{array}{l}\text { a. Pengenalan } \\
\text { masalah } \\
\text { b. Pencairan } \\
\text { informasi } \\
\text { c. Evaluasi } \\
\text { alternatif } \\
\text { d. Keputusan } \\
\text { membeli } \\
\text { e. Perilaku purna } \\
\text { beli } \\
\text { (Philip Kotler, } \\
\text { 2005) }\end{array}$ & $\begin{array}{l}\text { Diukur melalui } \\
\text { angket dengan } \\
\text { menggunakan } \\
\text { skala likert. }\end{array}$ \\
\hline
\end{tabular}

\section{Pembahasan}

\section{Uji Validitas}

1) Perubahan Biaya Transaksi Kartu ATM

Tabel 1 Perubahan Biaya Transaksi Kartu ATM

\begin{tabular}{|c|c|c|c|}
\hline & Total.X & Nilai r tabel & Status \\
\hline $\mathrm{X} 1$ &, $701^{* *}$ & 0,312 & Valid \\
\hline $\mathrm{X} 2$ &, $916^{* *}$ & 0,312 & Valid \\
\hline $\mathrm{X} 3$ &, $948^{* *}$ & 0,312 & Valid \\
\hline $\mathrm{X} 4$ &, $924^{* *}$ & 0,312 & Valid \\
\hline
\end{tabular}

Sumber: Data primer yang diolah, 2016

Dari tabel 1 di atas diperoleh $r$ tabel sebesar 0,312. Sehingga dapat dilihat bahwa nilai $r$ hitung $>r$ tabel sehingga pada taraf signifikasi 0.05 dapat disimpulkan bahwa semua item pertanyaan untuk perubahan biaya transaksi kartu ATM valid.

2) Minat Bertransaksi Nasabah (Y)

Tabel 2 Minat Bertransaksi Nasabah

\begin{tabular}{|l|r|r|r|}
\hline No & Total.Y & Nilai r table & \multicolumn{1}{c|}{ Status } \\
\hline Y1 &, $644^{* *}$ & 0,312 & Valid \\
\hline Y2 &,$^{*} 60^{* *}$ & 0,312 & Valid \\
\hline Y3 &, $577^{* *}$ & 0,312 & Valid \\
\hline Y4 &, $435^{* *}$ & 0,312 & Valid \\
\hline Y5 &, $606^{* *}$ & 0,312 & Valid \\
\hline Y6 &, $642^{* * *}$ & 0,312 & Valid \\
\hline Y7 &, $536^{* *}$ & 0,312 & Valid \\
\hline
\end{tabular}


Pengarub Perubahan Biaya Transaksi...

\begin{tabular}{|l|l|l|l|}
\hline Y8 & ,546 $^{* *}$ & 0,312 & Valid \\
\hline Y9 &, $693^{* *}$ & 0,312 & Valid \\
\hline Y10 &, $581^{* *}$ & 0,312 & Valid \\
\hline Y11 &, $508^{* * *}$ & 0,312 & Valid \\
\hline Y12 &, $666^{* *}$ & 0,312 & Valid \\
\hline
\end{tabular}

Sumber: Data primer yang diolah, 2016

Tabel 2 di atas diperoleh $\mathrm{r}$ tabel 0,312 dan dapat dilihat bahwa nilai $\mathrm{r}$ hitung $>\mathrm{r}$ tabel sehingga pada taraf signifikansi 0.05 dapat disimpulkan bahwa semua item pertanyaan untuk variabel minat bertransaksi nasabah valid.

\section{Uji Reliabilitas}

1) Perubahan Biaya Transaksi Kartu ATM

Tabel 3 Uji Reliabilitas Perubahan Biaya Transaksi Kartu ATM

\begin{tabular}{|c|c|c|}
\hline Cronbach's Alpha & $\begin{array}{c}\text { Cronbach's Alpha Based on } \\
\text { Standardized Items }\end{array}$ & N of Items \\
\hline, 901 &, 896 & 4 \\
\hline
\end{tabular}

Sumber: Data primer yang diolah, 2016

Dari tabel 3 di atas nilai Cronbach Alpha sebesar 0,901 >0.6 maka dapat disimpulkan 4 butir pertanyaan dari Perubahan Biaya Transaksi Kartu ATM adalah valid dan reliabel untuk mengukur pengaruhnya terhadap minat bertransaksi nasabah di BRISyariah KC Semarang.

2) Minat Bertransaksi Nasabah (Y)

Tabel 4 Uji Reliabilitas Minat Bertransaksi

\begin{tabular}{|c|c|c|c|}
\hline & $\begin{array}{c}\text { Cronbach's Alpha } \\
\text { Based on } \\
\text { Standardized } \\
\text { Items }\end{array}$ & N of Items & Status \\
\hline Cronbach's Alpha &, 832 & 12 & Reliabel \\
\hline, 825 & & 125 &
\end{tabular}

Sumber: Data primer yang diolah, 2016

Dari tabel 4 di atas nilai Cronbach Alpha sebesar $0.825>0.6$ maka dapat disimpulkan bahwa 12 pertanyaan dari variabel minat bertransaksi nasabah adalah valid dan reliabel untuk mengukur 
pengaruh perubahan biaya transaksi kartu ATM terhadap minat bertransaksi nasabah di BRISyariah KC Semarang.

\section{Uji Asumsi Klasik}

\section{1) Uji Heteroskedatisitas}

Uji Heteroskedastisitas bertujuan menguji apakah dalam model regresi terjadi ketidaksamaan varian dari residual satu pengamatan ke pengamatan yang lain. Untuk mendeteksi ada tidaknya heteroskedastisitas dengan melihat ada tidaknya pola tertentu.

Gambar 1 Uji Heteroskedatisitas

Scatterplot

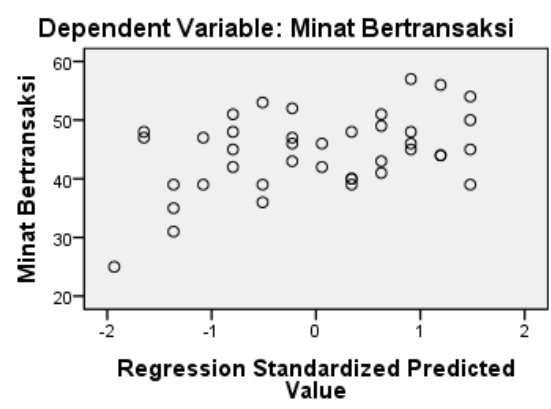

Dari gambar 1 tersebut terlihat titik-titik yang menyebar secara acak, tidak membentuk suatu pola tertentu yang jelas, serta tersebar baik di atas maupun di bawah angka 0 (nol) pada sumbu Y. Hal ini berarti tidak terjadi heteroskedastisitas pada model regresi.

\section{2) Uji Linearitas}

Dasar minat bertransaksi nasabah dalam uji linearitas dapat dilakukan dengan cara melihat nilai signifikansi pada Linearity. Pengujian ini dengan menggunakan Test for Linearity pada taraf signifikansi 0.05. Bila signifikansi kurang dari 0.05 maka dapat disimpulkan bahwa dua variabel tersebut terdapat hubungan linear secara signifikan. 
Pengarub Perubahan Biaya Transaksi...

Tabel 5 Anova Perubahan Biaya Transaksi Kartu ATM

\begin{tabular}{|c|c|c|c|c|c|c|}
\hline \multicolumn{7}{|c|}{ ANOVA $^{b}$} \\
\hline & & $\begin{array}{c}\text { Sum of } \\
\text { Squares }\end{array}$ & Df & Mean Square & $\mathrm{F}$ & Sig. \\
\hline \multirow[t]{3}{*}{1} & $\begin{array}{l}\text { Regressi } \\
\text { on }\end{array}$ & 297,763 & 1 & & 8,282 &, $007^{\mathrm{a}}$ \\
\hline & Residual & 1366,237 & 38 & 35,954 & & \\
\hline & Total & 1664,000 & 39 & & & \\
\hline
\end{tabular}

a. Predictors: (Constant), Perubahan Biaya Transaksi Kartu ATM

b. Dependent Variable: Minat Bertransaksi

Sumber: Data primer yang diolah, 2016

Berdasarkan nilai signifikansi dari tabel 5 di atas, diperoleh nilai signifikansi linearity 0.007 kurang dari 0.05, yang artinya terdapat hubungan linear secara signifikan antara perubahan biaya transaksi kartu ATM (X) dengan minat bertransaksi nasabah (Y)

\section{3) Uji Normalitas}

Uji normalitas bertujuan untuk menguji apakah dalam model regresi, variabel terikat dan variabel bebas keduanya mempunyai distribusi normal ataukah tidak. Model regresi yang baik adalah memiliki distribusi data normal atau mendekati normal. Data distribusi normal dapat dilihat dari penyebaran data (titik) pada sumbu diagonal.

Gambar 4.4 Uji Normalitas Minat Bertransaksi

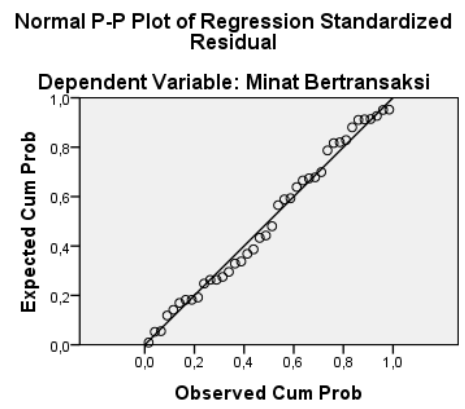

Jika dilihat berdasarkan grafik di atas, maka data dari semua data berdistribusi normal. Hal ini karena semua data menyebar mengikuti garis diagonal. 


\section{Uji Regresi Sederhana}

Analisis regresi linear sederhana digunakan untuk mengetahui hubungan atau pengaruh variabel independen yaitu perubahan biaya transaksi pada kartu ATM (X) terhadap variabel dependen yaitu minat bertransaksi nasabah di BRISyariah KC Semarang (Y).

Tabel 6 Hasil Regresi

Coefficients $^{\text {a }}$

\begin{tabular}{|c|c|c|c|c|c|c|}
\hline \multirow{2}{*}{\multicolumn{2}{|c|}{ Model }} & \multicolumn{2}{|c|}{$\begin{array}{c}\text { Unstandardized } \\
\text { Coefficients }\end{array}$} & \multirow{2}{*}{$\begin{array}{c}\text { Standardized } \\
\text { Coefficients } \\
\text { Beta }\end{array}$} & \multirow[b]{2}{*}{$\mathrm{T}$} & \multirow[b]{2}{*}{ Sig. } \\
\hline & & B & $\begin{array}{l}\text { Std. } \\
\text { Error }\end{array}$ & & & \\
\hline \multirow[t]{2}{*}{1} & (Constant) & 32,872 & 4,150 & & 7,921 & ,000 \\
\hline & $\begin{array}{l}\text { Perubahan } \\
\text { Biaya } \\
\text { Transaksi } \\
\text { Kartu ATM }\end{array}$ & ,786 & ,273 & ,423 & 2,878 & ,007 \\
\hline
\end{tabular}

a. Dependent Variable: Minat Bertransaksi

Sumber: Data Primer yang diolah, 2016

Berdasarkan tabel di atas, maka persamaan regresi yang terbentuk pada uji regresi ini adalah:

$Y=32,872+0,786 X$

1) Konstanta $=32,872$

Artinya jika perubahan biaya transaksi kartu ATM 0, maka minat bertransaksi nasabah positif atau naik sebesar 32,872.

2) Koefisien $=0,786$

Artinya jika jumlah perubahan biaya transaksi kartu ATM ditingkatkan sebesar 1 satuan maka, minat bertransaksi akan meningkat sebesar 0,786 .

\section{Uji Hipotesis}

\section{1) Uji Simultan (F test)}

Uji F dalam penelitian ini digunakan untuk mengetahui apakah variabel independent perubahan biaya transaksi kartu ATM berpengaruh secara simultan terhadap variabel dependent yaitu minat 
Pengaruh Perubahan Biaya Transaksi...

bertransaksi nasabah. Sementara itu untuk kriteria pengujiannya adalah jika $\mathrm{F}$ hitung $\leq \mathrm{F}$ tabel, maka Ho diterima dan Ha ditolak. Begitu juga sebaliknya jika F hitung $>$ F tabel, maka Ho ditolak dan Ha diterima.

Tabel 4.14 Hasil Uji F

\begin{tabular}{|c|c|c|c|c|c|c|}
\hline \multicolumn{7}{|c|}{ ANOVA $^{b}$} \\
\hline Model & & Sum of Squares & df & Mean Square & $\mathrm{F}$ & Sig. \\
\hline \multirow[t]{3}{*}{1} & Regression & 297,763 & 1 & 297,763 & 8,282 &, $007^{\mathrm{a}}$ \\
\hline & Residual & 1366,237 & 38 & 35,954 & & \\
\hline & Total & 1664,000 & 39 & & & \\
\hline
\end{tabular}

a. Predictors: (Constant), Perubahan Biaya Transaksi Kartu ATM

b. Dependent Variable: Minat Bertransaksi

Sumber: Data primer yang diolah. 2016

Dari tabel 4. hasil uji $\mathrm{F}$ model ANOVA diperoleh $\mathrm{F}$ hitung sebesar 8,282. Dengan menggunakan tingkat keyakinan 95\% dan $\alpha=$ $5 \%$. Diperoleh F tabel sebesar 4,10. Karena nilai Fhitung $(8,282)>$ nilai F tabel $(4,10)$, maka Ho ditolak dan Ha diterima. Maka perubahan biaya transaksi kartu ATM berpengaruh terhadap minat bertransaksi nasabah.

\section{2) Koefisien Determinasi $\left(\mathbf{R}^{2}\right)$}

Koefisien Determinasi $\left(\mathrm{R}^{2}\right)$ pada intinya mengukur seberapa jauh kemampuan model dalam menerangkan variasi variabel dependen. Nilai koefisien determinasi adalah antara nol dan satu.

Tabel 4.15 Hasil Uji Koefisien Determinasi $\left(\mathrm{R}^{2}\right)$

\begin{tabular}{|l|c|r|r|c|}
\hline \multicolumn{5}{|c|}{ Model Summary $^{\mathbf{b}}$} \\
Model & $\mathrm{R}$ & R Square & $\begin{array}{c}\text { Adjusted R } \\
\text { Square }\end{array}$ & $\begin{array}{c}\text { Std. Error of the } \\
\text { Estimate }\end{array}$ \\
\hline 1 &, $423^{\mathrm{a}}$ &, 179 &, 157 & 5,996 \\
\hline
\end{tabular}

\begin{tabular}{|l|r|r|r|r|r|r|}
\multicolumn{7}{|c|}{ Model Summary $^{\mathbf{b}}$} \\
\cline { 2 - 6 } \\
\cline { 2 - 6 } & Change Statistics & Durbin- \\
Model & R Square Change & F Change & df1 & df2 & $\begin{array}{c}\text { Sig. F } \\
\text { Change }\end{array}$ \\
\hline 1 &, 179 & 8,282 & 1 & 38 &, 007 & 2,065 \\
\hline
\end{tabular}

a. Predictors: (Constant), Perubahan Biaya Transaksi Kartu ATM

b. Dependent Variable: Minat Bertransaksi

Sumber: Data primer yang diolah. 2016

Dalam tabel 4.15 model summary menunjukkan bahwa nilai $\mathrm{R}$ Square $\left(\mathrm{R}^{2}\right)$ dalah 0.179 atau $17.9 \%$. Hal ini berarti bahwa variabel 
independen yaitu perubahan biaya transaksi kartu ATM mampu menjelaskan variabel dependen yaitu minat bertransaksi nasabah sebesar $17.9 \%$ dan selebihnya $82.1 \%$ ditentukan atau dijelaskan oleh variabel lain yang tidak termasuk dalam analisa atau penelitian regresi ini.

\section{3) Uji Parsial (t test)}

Uji ini digunakan untuk menguji ada tidaknya pengaruh variabel independen terhadap variabel dependen. Dengan menggunakan langkah-langkah sebagai berikut:

Ho : bi $=0$, artinya secara parsial tidak terdapat pengaruh yang positif dan sigbifikan dari variabel independen terhadap variabel dependen. Ha $: \mathrm{b} \neq 0$ artinya secara parsial terdapat pengaruh yang positif dan signifikan dari variabel independen terhadap variabel dependen. Ho diterima, apabila $\mathrm{t}$ hitung $<\mathrm{t}$ tabel pada $\alpha=0.05$. Ha diterima, apabila thitung $>\mathrm{t}$ tabel pada $\alpha=0.05$.

Tabel 4.16 Hasil Uji t Test

Coefficients $^{\mathrm{a}}$

\begin{tabular}{|c|c|c|c|c|c|c|}
\hline \multirow{2}{*}{\multicolumn{2}{|c|}{ Model }} & \multicolumn{2}{|c|}{$\begin{array}{l}\text { Unstandardized } \\
\text { Coefficients }\end{array}$} & \multirow{2}{*}{$\begin{array}{c}\text { Standardized } \\
\text { Coefficients } \\
\text { Beta } \\
\end{array}$} & \multirow[b]{2}{*}{$\mathrm{T}$} & \multirow[b]{2}{*}{ Sig. } \\
\hline & & B & $\begin{array}{l}\text { Std. } \\
\text { Error }\end{array}$ & & & \\
\hline \multirow[t]{2}{*}{1} & (Constant) & 32,872 & 4,150 & & 7,921 & ,000 \\
\hline & $\begin{array}{l}\text { Perubahan } \\
\text { Biaya } \\
\text { Transaksi } \\
\text { Kartu ATM }\end{array}$ & ,786 & ,273 & ,423 & 2,878 & ,007 \\
\hline
\end{tabular}

a. Dependent Variable: Minat Bertransaksi

Sumber: Data primer yang diolah, 2016

Pada tabel 4.16 diketahui bahwa $t$ hitung adalah 2,878 sedangkan nilai t tabel adalah 2,024, maka t tabel lebih kecil daripada $t$ hitung. Artinya perubahan biaya transaksi kartu ATM berpengaruh positif terhadap minat bertransaksi nasabah di BRISyariah $\mathrm{KC}$ Semarang. 
Pengarub Perubahan Biaya Transaksi...

\section{Kesimpulan}

Berdasarkan hasil analisis yang telah dilakukan, perubahan biaya transaksi kartu ATM memiliki pengaruh yang positif dan signifikan terhadap minat bertransaksi nasabah di BRISyariah KC Semarang. Dengan adanya perubahan biaya transaksi seperti tarik tunai, transfer, dan cek saldo yang saat ini mahal maka minat bertransaksi nasabah menjadi berkurang. Hal ini dibuktikan dengan nilai t hitung sebesar 2,878 > t tabel sebesar 2,024 dengan tingkat signifikan sebesar 0,000 dibawah 0,05. Sehingga hipotesis yang diajukan dalam penelitian ini dapat diterima. Dan nilai $\mathrm{R}$ Square $\left(\mathrm{R}^{2}\right)$ menunjukkan sebesar 0.179 atau $17.9 \%$. Hal ini berarti bahwa variabel independen yaitu perubahan biaya transaksi kartu ATM mampu menjelaskan variabel dependen yaitu minat bertransaksi nasabah sebesar $17.9 \%$ dan selebihnya $82.1 \%$ ditentukan atau dijelaskan oleh variabel lain tidak dalam cakupan penelitian penulis. Dengan kata lain, perubahan biaya transaksi kartu ATM pada tabungan Faedah mempengaruhi minat bertransaksi nasabah di BRISyariah KC Semarang sebesar $17.9 \%$. 
Imam Yabya \& Retnandi

\section{DAFTAR PUSTAKA}

Abdullah, Thamrin, Manajemen Pemasaran, Jakarta: PT RajaGrafindo Persada, 2013.

Ali, Zainuddin, Hukum Perbankan Syariah, Jakarta: Sinar Grafika, 2008.

Antonio, Muhammad Syafi'I, Bank Syariah dari Teori ke Praktik. Jakarta: Gema Insani, 2001.

Arifin, Zainul, Dasar-Dasar Manajemen Bank Syariah, Jakarta: Pustaka Alvabet, 2006.

Arikunto, Suharsimi, Prosedur Penelitian Suatu Pendekatan Praktik, Jakarta: PT. Rineka Cipta, 2006.

Brosur Tabungan Faedah BRISyariah iB sebelum terjadi perubahan biaya (Brosur lama)

Brosur Tabungan Faedah BRISyariah iB setelah terjadi perubahan biaya (Brosur terbaru)

Bungin, M. Burhan, Metodologi Penelitian Kuantitatif, Jakarta: Prenada Kencana Group, 2005.

-------, Metodologi Penelitian Kuantitatif Komunikasi, Ekonomi, dan Kebijakan Publik serta Imu-Imu Sosial Lainnya. Jakarta: Kencana, 2005.

Fauzi, Muchammad, "Pengaruh Kinerja Anjungan Tunai Mandiri (ATM) terhadap Kepercayaan Partisipasi Relationship dan Loyalitas Nasabah Bank Syariah di Jawa Tengah", Jurnal Pemikiran dan Penelitian Ekonomi Islam, Volume II, Edisi 1, Mei 2011.

Hasan, Ali, Marketing Bank Syariah, Bogor: Penerbit Ghalia Indonesia, 2010.

Indonesia, Majelis Ulama, Himpunan Fatwa Keuangan Syariab Dewan Syariah Nasional MUI. Jakarta: Erlangga, 2014.

Karim, Adiwarman, Bank Islam: Analisis Fiqih dan Kenangan, Jakarta: Rajawali, 2004.

Kasmir, Dasar-Dasar Perbankan Syariah. Jakarta: RajaGrafindo Persada, 2002.

-------, Bank dan Lembaga Keuangan Lainnya. Jakarta: PT Raja Grafindo Persada, 2003.

Kotler, Philip, Manajemen Pemasaran Jilid I, Jakarta: Indeks, 2005.

Mansur, Ekonomi Islam, Salatiga: STAIN Salatiga Press, 2009.

Muhammad, Sistem dan Prosedur Operasional Bank Syariah, Yogyakarta: UII Press, 2000.

Volume VII/Edisi 1/Mei 2016 
Pengarub Perubahan Biaya Transaksi...

--------, Manajemen Bank Syariah, Yogyakarta: AMPYKPN, 2002..

Prasetyo, Bambang, dan Lina Miftahul Jannah, Metode Penelitian Kuantitatif Teori dan Aplikasi, Jakarta: PT RajaGrafindo Persada, 2012.

Priyaatno, Duwi, Paham Analisis Statistik Data dengan SPSS, Yogyakarta: MediaKom, 2010

Saleh, Abdul Rahman dan Mubib Abdul Wahab, Psikologi Suatu Pengantar dalam Perspektif Islam. Jakarta: Prenada Media, 2004.

Siregar, Sofiyan, Metode Penelitian Kuantitatif: Dilengkapi Perbandingan Perbitungan Manual \& SPSS, Jakarta: Kencana, 2013.

Slameto, Belajar dan Faktor-faktor Yang Mempengarubinya, Jakarta: Rineka Cipta, 2010.

Soemitra, Andri, Bank \& Lembaga Keuangan Syariah, Jakarta: Kencana, 2009.

Sugiyono, Statistik Untuk Penelitian, Bandung: Alfabeta, 2005.

-------, Metode Penelitian Kuantitatif Kualitatif Dan R\&D, Bandung: Alfabeta, 2008.

-------, Metode Penelitian Bisnis. Bandung: Alfabeta. 2008.

-------, Metode Penelitian Kombinasi (Mixed Methods). Bandung: Alfabeta, 2011.

Sutanto, Herry dan Khaerul Umam, Manajemen Pemasaran Bank Syariah. Bandung: Pustaka Setia, 2013.

Sutedi, Adrian, Perbankan Syariah Tinjanan dan Beberapa Segi Hukum. Bogor: Ghalia Indonesia, 2009.

Umar, Husein, Metode Riset Bisnis. Jakarta: PT Gramedia Pustaka Utama, 2003.

Undang-Undang Nomor 21 tahun 2008 tentang Perbankan Syariah.

Usanti, Trisadini P dan Abd. Shomad., Transaksi Bank Syariah, Jakarta: PT Bumi Aksara, 2013.

Wawancara dengan Manajer Operasional BRISyariah KC Semarang pada tanggal 15 April 2016 Pukul 17.15 WIB.

Widilestariningtyas, Ony, et al, Akuntansi Biaya, 2008, Yogyakarta: Graha Ilmu, 2008.

Widiyono, Try, Aspek Hukum Operasional Transaksi Produk Perbankan di Indonesia. Bogor: Ghalia Indonesia, 2006.

www.brisyariah.co.id, diakses 1 Maret 2016. 